contents of the flowing river. One old woman, however, dispelled the Templar's idea by stating that she had felt the smell of 'brumstane' near her dwelling, and on searching the premises it was found the water-barrel had got a saffron cap on, and was otherwise dusted with the subtle, powder. As this mystery, if it is not explained, may prove serious to the nervous, superstitious, or credulous part of the community we may as well add that at this season districts in the neighbourbood of fir plantations run the risk of a thorough dusting of this powder if there is the slightest breeze, as the cones of the young Scots fir are thickly coated with yellow powder or pollen, which will give out a blinding saffron cloud on the slightest irritation."

The laudable desire of our newspaper correspondent to relieve the anxieties of his neighbours at a time when the Presbyterian world is much exercised over the question of eternal and sulphureous punishment, can be fully appreciated only by natives. But in my opinion, the correspondent, in his clear knowledge of the nature of the "brimstone" deposit, exhibits a most praiseworthy tendency to explain the natural in terms of the natural; whilst the incident tends to show at the same time that there are not a few persons in this world to whom a course of elementary studies in natural history would serve as a means of culture, not to say of common protection against ludicrous mistakes such as those against which $\mathrm{Mr}$. Carpenter inveighs. ANDREW WILSON

Edinburgh Medical School

\section{Plague of Rats}

I ser by Nature, vol. xx. p. 65, that Mr. Orville A. Derby contributes some very interesting information relating to a plague of rats in Brazil, and adding that the plague "is said to occur at intervals of about thirty years, and to be simultaneous with the drying of the Taquara, or bamboo, which everywhere abounds in the Brazilian forests." It may be interesting to know that a similar plague of rats visited the higher coffee districts of Ceylon during the year 1875 , doing great damage to young and old plantations alike.

It is remarkable that the invasion of rats was simultaneous with the flowering and death of the Nilloo (Strobilanthes), which forms the greater part of the underwood of Ceylon forests, and is said to flower and die once every seven years. The most remarkable part of the plagte was that the rats did not seem to devour any part of the branches they cut ofi, but to nip off and leave them untouched upon the ground. So serious indeed was the damage done, that on some coffee estates rewards were given to coolies for every rat they caught, and it was not an uncommon thing to hear of three or four hundred rats being destroyed, on one estate only, per week.

Between the years 1840 and 1850 there was a similar plague in the Kalebokka coffee district, where the damage done was immense, but I an not aware if it was so general as in the rat plague of 1875 . It is to be hoped that we may not again be invaded in 1882 , when the Nilloo is next expected to die.

Ballangoda, Ceylon, June 16

FREDERICK LEWIS

\section{Glow-worms}

SHELLEY sings of a "glow-worm golden in a dell of dew," but last night, at 1o o'clock, while travelling on a bridle path amcng the bleak lonely mountains of Tynron, Dumfriesshire, bearing up against a high wind with cold rain, I espied three glow-worms shining among the grass and ferns. I had seen them in the same locality before, but scarcely expected to have noticed them in such ungenial weather when summer has with us scarcely yet begun. July 8

J. S.

\section{Headless Butterfly laying Eggs}

Anour three o'clock on the 11 th inst. I picked up a butterfly, probably belonging to the genus Vanessa. It was a female, the head of which had recently been plucked off by a bird, and was lying near the body. 'Thiuking it was dead, I carried it home to examine the wing scales. On clipping off a bit of wing about four hours afterwards, the legs moved, and in a short time an egg was laid. In about two minutes another egg was laid. Others followed, till five-and-twenty had been expelled. Tremors of the legs and wings accompanied each deposit. The laying ceased, and the headless mother seemed dexd. Next morning, on touching her, the motions of the less and wings were repeated, and in a short time the laying was resumed. On close examination a heaving of the wings and rings of the abdomen could be observed, with about the frequency of human breathing. At the end of twenty-nine and a half hours from the time of finding, the laying ceased; seventy-eight eggs were laid by the butterfly with her head off.

North Kinmundy, Aberdeen, July 14

A. STEPHEN WILSON

\section{THE COMPARATIVE ANATOMY OF MAN}

III.

The Mongoloid People of Asia

TO the north and east of the line already spoken of, running northwards from the head of the Bay of Bengal to the north of the Caspian Sea, the bulk of the people of the Continent of Asia belong to the Mongolian, or better, Mongoloid type.

The physical characters of these people, best seen in the so-called Tartars who inhabit the country to the north of the great wall of China, are as follows: the complexion is pale brown, usually with a yellowish tinge; hence they are spoken of as the "yellow races," in contradistinction to the (50-called) white and black races. Their hair is black; perfectly straight, and coarse. In microscopic section it is seen to be of large size, and more inclining to cylindrical than in other races, but it varies much. Except on the scalp, where the hair is often long, the capillary development is very scanty. On the face it is often limited to two slender pencils on the upper lip; and the beard, when developed, is acquired comparatively late in life. The face is broad and flat; the space between the eyes is wide; the nose small, straight, and compressed; the eyes dark and small; the aperture between the lids narrow and somewhat oblique, being raised at the outer corner ; the upper lid drooping, the inner corner partly covered by a vertical crescentic fold of skin; the cheeks very prominent; the mouth and lips of moderate size, the lower lip often hanging; the chin small and sharp.

The osteological characters of the typical Mongolian are more marked in the face than in the cranium, for the latter may vary between the extremes, of brachycephaly and dolichocephaly, though the former prevails. The face is large, being both high and broad; the forehead flat, the glabella and superorbital ridges slightly developed; the orbits round, with thin sharp margins, the sub-glabellar nasal depression very slight; the nasal bones narrow and flat; the whole framework of the nose inclining to the leptorhine form; the jaws of medium prominence; the arch of the mouth broad and round; the malar bones both broad and deep. Perhaps the most distinctive feature of the Mongoloid face, which gives it the characteristic appearance, is the forward position of the outer margin of the orbit, as compared with the median line of the face. In order to estimate this character with exactness, Prof. Flower measures the angle formed between two horizontal lines meeting at the most depressed point of the nasal bones in the middle line (the apex of the angle) and resting on the middle of the outer margins of the orbit. This nasi-malar angle gives valuable average results. For instance, the average of I 30 European skulls is I3I deg., of the twenty Maravars mentioned in the last abstract, exactly the same; of 20 African negroes I 34 deg., and of 20 Australians $135 \mathrm{deg}$. In all of the true Mongolian races, the average exceeds 140 deg. Thus, in 4 Samoyedes it is 144 deg. ; in 16 Chinese, 142 deg.; in 7 Japanese, 14I deg. ; in 4 Burmese, I 44 deg.; in 26 Eskimo, 144 deg.

The Mongoloid races of Asia are conveniently divided into two groups, the northern and the southern. The former, called Mongolo-Altaic races, are united by languages having considerable affinities. They nearly all lead a nomadic life, clepending for their living on bunting, fish-

$x$ Abstract of Prof. Flower's Hunterian Lectures, delivered at the Roya College of Surgeons, commencing on Wednesday, March 5. Continued from p. 246. 